\title{
MEDIA ARCHITECTURE AND INTERACTIVE ART INSTALLATIONS STIMULATING HUMAN INVOLVEMENT AND ACTIVITIES IN PUBLIC SPACES
}

\author{
Katarzyna Urbanowicz ${ }^{1}$, Lucyna Nyka ${ }^{2}$
}

\begin{abstract}
This paper examines the potential for media architecture and interactive art installations to stimulate human involvement and activities in public spaces. On the basis of theoretical approaches, case studies and interdisciplinary surveys, the paper provides insight into how screens projecting media and interactive installations in city spaces can inspire people to become active on many levels. The research is focused, both on temporary and permanent art installations, that support new technologies to encourage people to interact with art objects and become actors in an urban performance. Media and interactive art can positively contribute to the urban landscape, foster public involvement, increase intensity of public life, and effectively enhance the identity of urban communities. The paper shows that, despite this potential for media architecture and interactive art projects, specific pre-conditions are needed for their success in urban environments. The paper focuses on the convergence of scale between the intervention itself and the assumed urban strategy, as well as on the time allowed for individual perception and active participation of people in the particular urban art scenario. As the research shows, the promotion of art pieces, through guided tours of the city, tends to reduce the perception of the installations themselves and almost excludes social interactions. Thus, while not so spectacular in scale, image, or number of visits, modest interventions that involve locals and allow time for relationship building between people, could be most effective in reaching urban renewal objectives.
\end{abstract}

UDC Classification: 7.07, DOI: http://dx.doi.org/10.12955/cbup.v4.819

Keywords: interactive installations, media architecture, public space, social encounters.

\section{Introduction}

In recent years, media architecture and interactive installations have become increasingly present in urban landscapes. The application of new technologies in art and architecture frequently produces astonishing and surprisingly positive effects on peoples' perception, feelings, and behavior. Despite the blame attributed to new technologies for impoverishing social contacts and poor quality of public life, today's media art installations are increasingly being perceived as catalysts of change. As previously demonstrated, interactive installations and new media art are powerful in stimulating human senses and improving the non-visual aspects of space (Urbanowicz \& Nyka, 2012). This paper showed that, paradoxically, despite the technological nature, modern art forms can contribute to both digital and direct social encounters. Such art form is used to create lively spaces, where people may interact with the installation itself or with one another, or at least remain passively in the city space observing the work of art and other users of the space. However, in order to achieve these lively spaces, it is crucial to define necessary pre-conditions and identify the various factors that increase the effectiveness of such projects and art interventions.

\section{Human Engagement into the Public Life in the Contemporary City Spaces}

One of the most crucial criteria in evaluating quality and functionality of a city space is the practical usage of the space by the city dwellers. A well-known urban planner and researcher, Gehl (2011, p. 15) emphasized: "precisely the presence of other people, activities, events, inspiration and stimulation comprise one of the most important qualities of public spaces altogether". Gehl (2011) explored the topic of vivid public spaces and analyzed human nature and behaviors in the context of conditions created for pedestrians in the city. He defined three types of outdoor activities: necessary activities, optional activities, and social ones. Necessary activities, such as walking for a bus, as well as some optional activities, are observed in most spaces in most cities worldwide. However, it is the last group mentioned, the social activities that are most important for public spaces, though it is also the most problematic for cities to manage.

Social activities depend on the presence of people in public spaces and occur when people linger to enjoy the surrounds, talking to others, observing together a street entertainer, and sharing smiles and

\footnotetext{
${ }^{1}$ Katarzyna Urbanowicz, Faculty of Architecture, Gdansk University of Technology, k.urbanowicz@pg.gda.pl

${ }^{2}$ Lucyna Nyka, Faculty of Architecture, Gdansk University of Technology, lnyka@pg.gda.pl
} 
opinions (Gehl, 2010). Passive contacts, such as simply seeing or hearing other people, are also considered social activities. Passive contact is considered the most widespread social activity in city streets, as well as in city centers, but as Gehl $(2011$, p. 13) states: "even this modest type of activity can be very appealing".

Contemporary city spaces are occasionally unstimulating and not always comfortable for human encounters. As Sennett (1994, p. 366) noticed: "Individual bodies moving through urban space gradually become detached from the space in which they moved, and from the people the space contained. As space became devalued through motion, individuals gradually lost a sense of sharing a fate with others" and "individuals create something like ghettos in their bodily experience". The problem is complex and many researchers and professionals from various disciplines, including sociologists, urban planners, architects, and artists, are exploring both the grounds as well as the possible solutions to improve the situation.

Many programs have been applied and methods developed to revive public spaces. Several have been focused on integrating people around elemental qualities of nature, which are today being reintroduced to cities. Numerous water installations and river squares or paths entice people to sit and look around, or wade through water, and thus allow them to experience particular environmental conditions in relation to themselves and others. At the same time, there is a growing interest in media architecture and interactive art installations located in public places. The simultaneity of these two phenomena is not coincidental, as was revealed by Nyka (2006). Both, elements of nature and technologically, support responsive environments activated by movement of people through space, and could be presumed different outcomes of the same pursuit in creating a new quality of urban landscape, one more sensitive and another reciprocal in reaction. This landscape, of both cultural and social construct, does not only mirror our changing society, as Cosgrove (1998) notes, but also appears today as 'fertile' ground for communicating among ourselves and finding relationships with others.

As Scott McQuire (2008, p. 132) suggested, the "experimental practices of contemporary media art can offer a useful test-bed for exploring the critical potential of relational space - the demand to actively construct social relations to others across heterogeneous spatio-temporal regimes - by promoting new forms of public agency". In fact, many experiments and fresh new ideas concerning the implementation of the new media art and interactive technologies are being applied and tested in public spaces, and quite often they prove surprisingly successful in the field of public life revival.

Media and Interactive Installations Stimulating Human Involvement and Activities in Public Spaces

There are numerous examples of successful and well-known interactive art interventions worldwide, such as, the Crown Fountain, designed by Jaume Plensa in Millennium Park, Chicago, which has created a new symbol for the citizens' identity and attracts thousands of people every day. There is a well-known project by Rafael Lozano-Hemmer, Body Movies, which is viewed across the world and has temporarily activated public spaces in many different cities. So many different forms of artistic expression are presented by such projects that invite people nearby to become co-creators of the work of art. The passerby changes from passive observers to active participants.

Although engaging an audience in creation of art work is not a novel concept, locating new art media directly on the streets adds a new quality. Thus, while being a legacy of the Fluxus movement, American Process and Conceptual Art, or the Joseph Beuys' experiments on 'social sculpture', today's participatory artistic performances and processes attract, incomparably, a wide group of people, a major part of which may never access an art gallery. The audience is encouraged to express its presence, feelings, and emotions. This functionality reveals a practicable, powerful new function of art in a contemporary city. Referring to 'media city', McQuire (2008, p.149) described this function: "not as the belated response to an already existing social world, but as an integral part of the construction of social relationships". This new interactive art, based on human attention and involvement, was distinguished by Lacy (1994, p. 19) as "new genre public art" and "visual art that uses both traditional and non-traditional media to communicate and interact with a broad and diversified audience about issues directly relevant to their lives" and, thus, in opposition to what has been called public art, it is based on engagement.

According to Simanowski (2011, p. 23), "interactivity is the sine qua non in digital media and the inevitable feature of digital art". From this, questions about how the interactivity worked, why it 
engaged people, and finally how it possibly supported social relations in space. Haque (2006) stated that interaction concerns exchange of information between people, machines, or between a person and a machine. In his opinion, these transactions should be circular and thus create a 'multiple-loop' interaction, depending on the 'conversational creativity' of both interacting systems. Such an "ephemeral form of communication and interaction augmented by technology" has been defined as a 'shared encounter' (Fatah gen Schieck, Kostakos, \& Penn, 2010, p. 180). It has also been described as "the interaction between two people or within a group where a sense of performative co-presence is experienced and which is characterized by a mutual recognition of spatial or social proximity" (Willis, Roussos, Chorianopoulos, \& Struppek, 2010, p. 4). In recent years, due to Intelligent Adaptive Systems, interactions have become more sophisticated and alluring for the user. The sensors with embedded controllers are programmed to learn from the environment and from interactions over time, to optimize and develop their behavior. The reactions are less mechanical and more creative, and likened to that of another lively being.

As previously observed, common actions and experiences, as well as unexpected and unusual events, may result from social encounters, even the simplest ones, such as, initiating a conversation (Gehl, 2011). This type of phenomenon was examined in past decades by Whyte (2001) in his outstanding book, The Social Life of Small Urban Spaces, and described with the term, triangulation. This starts with relating interactions that appear between the street artists and the audience. For example, spectators ' $\mathrm{A}$ ' and ' $\mathrm{B}$ ' may share a smile or start to talk, admiring the skills and talents of the performer ' $\mathrm{C}$ '. In this context, the installation is performer $\mathrm{C}$, who is the 'trigger' for attracting people to stay in the space and to interact and play, as well as for spontaneous social encounters. This ends with all people being present in the space, performing on different levels of activity, and creating a lively social spectacle.

When the media facade or art installation 'seduces' a person to interact, a number of subsequent social activities result. People interacting with the art installation become actors in the space. Other people tend to either join or observe the 'performers', and frequently they start to converse with each other, comment, or explain the situation that they are experiencing together. The 'Shared Encounters' can be differentiated into sub-topics, such as, shared experience, playful encounters, spatial settings, and social glue (Willis, et al., 2010). The type of installation and its interaction mode will determine whether it is a screen projecting media that is interactive by means of a special remote device, a personal smartphone, or a person's own body, or alternatively as a spatial 'responsive environment' (Bullivant, 2006), 'relational architecture' (Adriaansens \& Brouwer, 2002), or 'interactive landscape' (Roosegaarde, 2010). Hence, there are different socio-scenarios and conditions to successfully affect the social public life.

\section{Studies on the Pre-conditions for Media Architecture and Interactive Art Location}

Numerous case studies, employed by researchers investigating interactive installations and media architecture, reveal a wide range of social activities, triggered by these projects. However, the effectiveness of stimulating such activities depends on several factors, of which, the exact location of the art is one of the most important. Members of a research group within the Bartlett School of Graduate Studies, University College London (Fatah gen. Schieck, Briones \& Mottram, 2007) examined such pre-conditions, and related these with the effect of particular installations on the actual urban landscape. As a case study, the researchers investigated the social reactions to light-emitting diodes (LEDs) of Urban Carpet, a digital urban ground, located in various parts of the city, Bath. A wide range of behavior patterns and levels of awareness were observed, allowing the researchers to designate a set of common practices, from curiosity and passive observation through to experience and engagement and a socializing platform, which involved interactions between friends and even strangers. In conclusion, researchers suggested that "the ability of an interactive large urban display to enhance social interaction depends on the social atmosphere where it is located, the type of audience and cultural background, the affordance of the prototype, and the affordance of the environment where it is located" (Briones, Fatah gen Schieck, \& Mottram, 2007, p. 5). The observations showed that "public interactive installations may provide a stage for emergent social interactions among various people. However, situating the digital installations in various locations, depending on the context, might generate diverse and unpredicted social behaviors we, as designers, are unaware of" (Fatah gen Schieck et al., 2007, p. 4). 
Another group of researchers focused their attention on urban screens and displays, detecting preconditions for the successful involvement of people. Among other issues, such as affordance of the place for locating the screen, there was the problem of scale discrepancy between media facades and interactive modules that complemented the computer generated images. This issue was examined in frames of the workshop, Urban HCI: Interactive Media Architecture and Disproportionate Scale, which was an accompanying event for the Media Architecture Biennale 2012. The authors, Patrick Tobias Fisher and Sven Gehring, demonstrated a diversity of spaces generated in front of a media façade, in which different human interactions and behaviors occur. A series of exercises helped the participants to understand, as authors expressed "where exactly the imbalance between human, interface, and the medium of the façade is created" (Fisher \& Gehring, 2012). It appeared the importance was not only a matter of proposing a successful interactive art installation, but also a matter of knowledge about how to place it properly in a specific public space and the degree of dependence on certain factors and conditions.

Fisher and Hornecker (2012) specified a typology of relevant types of spaces for interactions to occur with Media Facades or Urban Screens in the city spaces, such as, Display Spaces, Interaction Spaces, Potential Interaction Spaces, Gap Spaces, Social Interaction Spaces, Comfort Spaces, and Activation Spaces. The authors believed that such identification would allow future designers to create a proper strategy for new installations or would become a guide for re-locating an existing installation to a new place.

\section{Studies on Pre-Conditions for Sharing Experiences - the Narratives Festival in Gdańsk}

An interesting research laboratory emerges today with the numerous festivals of media and interactive art being conducted in many cities across the world. It is a slightly alternative observation context, as the participants are barely random, being mostly visitors who have planned to participate and experience the event. These visitors arrive with certain expectations, though are open to the situations they find. Such festivals are mostly temporary, but tend to be cyclic events, usually quite powerful in gathering large numbers of people, locals, and tourists, to visit the city and follow the sites of the art interventions. Such events illuminate the city after dark and allow observers to perceive an alternate side to the well-known spaces, as well as the peculiar qualities of the places they have yet to discover.

With hindsight, history shows that these festivities took place across rural Europe from societal beginnings, starting with the traditional festivals of light in Italy and Scandinavia. As Cianchetta (2009, p. 154) states: "Light becomes a tool for the re-enchantment of urban experience and for the redefinition of metropolitan attractiveness in a simple metaphor of radiance". Cianchetta observed that, currently, the 'new nocturnal formats' aim to renew the relationship between visitors and inhabitants to the urban setting. "The objective is to create a new urban memory, a present which has its own narratives and recurrences" (Cianchetta, 2009, p. 147). Certainly the art festivals of media and interactive art interventions in the public spaces have a potential to influence the perception of space and attitude towards it, creating new identities.

The artistic project, Festival Narratives: Installations and Interventions in Public Space, has been organized in Gdansk, Poland, since 2009. Although starting as an almost unnoticed event, taking place over a few days in the historical city center, it has developed into a large outdoor exhibition, visited by thousands of people. Together, the festival and its rising popularity moved to more abandoned spaces, including more forgotten or problematic districts. Each year, the festival has consisted of a number of art interventions, such as public artworks, façade projections, and interactive installations, located in chosen spots, along several possible connecting paths. The positions of these spots are marked on special maps, distributed during the event and available online. As a parallel option, a guided tour has been provided, which, in the first years, the festival curator, once daily, showed interest in this option with groups of up to 30 participants. In subsequent years, the guided tours were scheduled every 20 minutes during the 'open' hours of the festival, with tour groups consisting of hundreds of people, following volunteers on a specified cultural walk through the main art interventions.

The observation and research conducted during the festival editions showed that these 'shared encounters' achieved more successful social interaction among strangers when conducted in relatively small groups and without a guide. On one hand, when following the guide, people tended to focus only on keeping with the group and not feeling connected to other people, and thus, they failed to 
experience the art intervention in the full dimension. On the other hand, people who had visited the places independently or with others who did not strictly follow the guided tour, activated the spaces for much longer, not only focusing on the art pieces, but also creating social encounters. As members of larger groups, people rarely initiated contact with other group members, whereas in choosing their own path, most often, they met the same strangers in several locations and this created a much stronger feeling of a spontaneous common experience in discovering the city. In searching for similar goals and interest points, people approached others for help in guidance with the map of installations, commenting on the impressions, or simply exchanging smiles. Possibly, these shared experiences are overcoming, at least temporarily, the estrangement of contemporary urban life from landscape, in this case, technologically enhanced, and from other people.

\section{Conclusion}

Contemporary city spaces are frequently lacking in stimulation or inspiring landscape for human encounters. In this context, media and interactive installations may have the power to increase the intensity of public life by supporting city spaces with ambiance to create meaningful co-presence of people and conditions for creative cooperation. A predominant goal of such artistic and architectural intervention is to empower people to actively participate in the artwork, and thus, to animate the space and change it into an inspiring platform for social encounters. The advancement of innovative technologies and notable steps towards achieving a new quality of urban landscape, more sensitive and reciprocal in reactions, significantly fosters public involvement. Visual effects that are unpredictable, more personal, and intellectually challenging in comparison to the predetermined schemes or fixed images applied in the first urban media art projects, are interactive participatory installations to engage the passers-by, local city dwellers, or even stakeholders.

Although the influence of media and interactive installations on human relations could be extremely powerful, there are specific pre-conditions that should be recognized and considered for their success in the urban environment. Studies indicate that the relevance of the preconditions pertain to the character of the space, its social atmosphere, type and cultural background of the audience, the location of the installation in the space, the affordance of the installation and its environment, and the scale convergence between the installation or media facade and the space where it is located. Moreover, an important precondition appears to be the time allowed for individual perception and active participation in a particular urban art scenario. Excluding this factor could significantly limit the positive impact of media and interactive art interventions, many of which are introduced in urban spaces only temporarily, mostly within specific art events, such as the 'light festivals' that are focused on a wider audience of citizens and visitors. As research has shown, promotion of art pieces through guided tours in the city tends to reduce visitors' observations of the installations and almost excludes social interactions. The visitors are more preoccupied with following the guide and gathering information than in experiencing the urban environment, experimenting on the effect they can exert on the space, or sharing opinions with others. This finding is particularly important with art interventions designed to support urban renewal that is focused on selected dilapidated city areas. The spectacular light festivals, by definition, gather international groups of visitors and quite often demand guided tours through the city. Thus, the moderate or even small scale media and interactive art interventions that focus on creating and inspiring meeting points to encourage locals to converse, will better suit the urban renewal objectives. Despite their limited scale, such projects activate the use of space for longer, and in a more sustainable manner than traditional center spaces. Providing a new set of images, along with shared experiences and memories, these projects have the power to add new value to observing places and effectively enhance the identity of urban communities.

\section{References}

Adriaansens, A., \& Brouwer, J. (2002). Alien Reationships from Public Space. In Transurbanism (pp. 138-143). Rotterdam: V2_Publishing/NAI Publishers. Retrieved from http://www.lozano-hemmer.com/publications.php

Briones, C., Fatah gen. Schieck, A., \& Mottram, C. (2007). A Socializing Interactive Installation for the Urban Environments. IADIS Applied Computing 2007. Retrieved from http://eprints.ucl.ac.uk/7459/1/7459.pdf

Bullivant, L. (2006). Responsive Environments. London: V\&A Publications.

Cianchetta, A. (2009). City by Night: The Illuminated City. In M. Armengaud, M. Armengaud, \& A. Cianchetta (Eds.), Nightscapes: Nocturnal Landscapes (pp. 105-164). Barcelona: Gustavo Gili SL 
Cosgrove, D. E. (1998). Social Formation and Symbolic Language. Wisconsin: University of Wisconsin Press.

Fatah gen. Schieck, A., Briones, C., \& Mottram, C. (2007). A Sense of Place and Pervasive Computing within the Urban Landscape. Space Syntax 6th International Symposium. Retrieved from http://discovery.ucl.ac.uk/7450/

Fatah gen Schieck, A., Kostakos, V., \& Penn, A. (2010). Exploring Digital Encounters in Public Arena. In K. S. Willis, G. Roussos, K. Chorianopoulos, M., \& Struppek, M. (Eds.), Shared Encounters (pp. 179-196). London: Springer.

Fisher, P. T., \& Gehring, S. (2012) URBAN HCI: Interactive Media Architecture and Disproportionate Scale [Workshop description]. Retrieved from http://mab12.mediaarchitecture.org/workshops/

Fischer, P. T., \& Hornecker, E. (2012). Urban HCI: spatial aspects in the design of shared encounters for media facades. Proceedings of the SIGCHI Conference on Human Factors in Computing Systems, Austin, Texas, USA. Retrieved from: doi $>10.1145 / 2207676.2207719$

Gehl, J. (2010). Cities for People. Washington, DC: Island Press.

Gehl, J. (2011). Life Between Buildings: Using Public Space. Washington, DC: Island Press.

Haque, U. (2006). Architecture, Interaction, Systems. [Extended version of a paper written for Arquitetura \& Urbanismo, AU 149]. Retrieved from www.haque.co.uk

Lacy, S. (1994). Cultural Pilgrimages and Methaphoric Journeys. In S. Lacy (Ed.), Mapping the Terrain: New Genre Public Art, Seattle-Washington: Bay Press.

McQuire, S. (2008). The Media City: Media, Architecture and Urban Space. Los Angeles, London, New Delhi, Singapore, Washington DC: Sage Publications.

Nyka, L. (2006). From Architecture of Circulations to Urban Landscapes. Gdansk: Gdansk University of Technology Press. Roosegaarde, D. (2010). Interactive Landscapes. Rotterdam: Nai Publishers.

Sennett, R. (1994). Flesh and Stone: The Body and the City in Western Civilization. New York: Norton.

Simanowski, R. (2011). Digital Art and Meaning: Reading Kinetic Poetry, Text Machines, Mapping Art, and Interactive Installations. Minneapolis, London: University of Minnesota Press.

Urbanowicz, K., \& Nyka, L. (2012). Media Architecture: Participation through the Senses. In MAB '12: Proceedings of the 4th Media Architecture Biennale Conference: Participation. New York, NY, USA: ACM, 51-54. http://doi.acm.org/10.1145/2421076.2421085

Willis, K. S., Roussos, G., Chorianopoulos, K., \& Struppek, M. (2010). Shared Encounters. In K. S. Willis, G. Roussos, K. Chorianopoulos, \& M. Struppek (Eds.), Shared Encounters (pp. 1-15). London: Springer.

Whyte, W. H. (2001). The Social Life of Small Urban Spaces. New York: Project for Public Spaces. (Original work published 1980) 